Brief research report

\title{
Body image and personality among British men: Associations between the Big Five personality domains, drive for muscularity, and body appreciation
}

\author{
Karis Benford ${ }^{\mathrm{a}}$, Viren Swami ${ }^{\mathrm{a}, \mathrm{b}, *}$ \\ a Department of Psychology, University of Westminster, London, UK \\ ${ }^{\mathrm{b}}$ Department of Psychology, HELP University College, Kuala Lumpur, Malaysia
}

\section{A R T I C L E I N F O}

\section{Article history:}

Received 25 February 2014

Received in revised form 11 July 2014

Accepted 14 July 2014

\section{Keywords:}

Personality

Big Five

Drive for muscularity

Body appreciation

Body mass index

\begin{abstract}
A B S T R A C T
The present study examined associations between the Big Five personality domains and measures of men's body image. A total of 509 men from the community in London, UK, completed measures of drive for muscularity, body appreciation, the Big Five domains, and subjective social status, and provided their demographic details. The results of a hierarchical regression showed that, once the effects of participant body mass index (BMI) and subjective social status had been accounted for, men's drive for muscularity was significantly predicted by Neuroticism $(\beta=.29)$. In addition, taking into account the effects of BMI and subjective social status, men's body appreciation was significantly predicted by Neuroticism $(\beta=-.35)$ and Extraversion $(\beta=.12)$. These findings highlight potential avenues for the development of intervention approaches based on the relationship between the Big Five personality traits and body image.
\end{abstract}

(c) 2014 Elsevier Ltd. All rights reserved.

\section{Introduction}

Emerging consensus among differential psychologists suggests that personality characteristics can be organised in terms of five broad trait domains (John, Naumann, \& Soto, 2008). Specifically, the Big Five - Openness to Experience, Conscientiousness, Extraversion, Agreeableness, and Neuroticism - are higher-order clusters that are thought to capture much of the variability in personality traits (John \& Srivastava, 1999). There is robust evidence to suggest that these domains predict individual differences in a wide range of settings, including mental and physical health, work performance, and academic success (John, Robins, \& Pervin, 2008). In addition, there is evidence that the Big Five domains are associated with corporeal experiences, including disordered eating (e.g., McLaren \& Best, 2009).

A growing body of research has further highlighted associations between personality, Neuroticism in particular, and body image. For example, women who score more highly on Neuroticism have poorer appearance evaluation (e.g., Davis, Dionne, \& Shuster, 2001; Kvalem, von Soest, Roald, \& Skolleborg, 2006),

\footnotetext{
* Corresponding author at: Department of Psychology, University of Westminster, 309 Regent Street, London W1B 2UW, UK. Tel.: +44 2079115000.

E-mail addresses: v.swami@westminster.ac.uk, virenswami@hotmail.com (V. Swami).
}

greater dissatisfaction with facial appearance (Thomas \& Goldberg, 1995), higher weight preoccupation (Davis, Shuster, Blackmore, \& Fox, 2004), lower body appreciation (Swami, Hadji-Michael, \& Furnham, 2008; Swami et al., 2013), and greater actual-ideal weight discrepancy (Swami, Taylor, \& Carvalho, 2011; Swami et al., 2013). In explanation, it has been proposed that individuals who score highly on Neuroticism are more likely to experience negative emotional states and to become easily dissatisfied, which places them at risk for negative body image (Swami et al., 2013). In addition, individuals who score highly on Neuroticism may also be more sensitive to appearance evaluation and rejection, which heightens drives to attain ideals of beauty, which in turn places them at risk for negative body image.

One limitation of this body of research is the focus on body image among women, to the relative exclusion of men. This is important because, in contrast to the drive for thinness reported among most women, men tend to endorse simultaneous desires to reduce body fat and to increase muscle mass. It is relative to a muscular ideal that many men manage their corporeal cognitions and behaviours (Thompson \& Cafri, 2007). For example, studies consistently show that men score higher on drive for muscularity than women and that higher drive for muscularity in men is associated with symptoms of poorer mental health (McCreary, 2007). Among men, Neuroticism may influence drive for muscularity: one previous study reported that Neuroticism predicted drive for muscularity, but did not moderate the effect of other 
psychological variables (e.g., perfectionism; Davis, Karvinen, \& McCreary, 2005).

Even so, there are a number of ways in which current knowledge can be extended. First, Davis et al. (2005) only included a measure of Neuroticism and, as such, it remains unclear whether other Big Five domains are associated with men's drive for muscularity. Certainly, among women, greater Extraversion has been associated with stronger dissatisfaction with facial appearance (Thomas \& Goldberg, 1995), but also more positive appearance evaluation (Kvalem et al., 2006), more positive body appreciation (Swami et al., 2008, 2013), and lower actual-ideal weight discrepancy (Swami et al., 2013). In addition, at least one study has reported a positive, albeit weak, association between Agreeableness and body appreciation among women (Swami et al., 2013). Thus, examining direct associations between the Big Five domains and men's drive for muscularity remains an important step for further research.

Second, although drive for muscularity is the dominant way in which men's body image has been conceptualised, it should not obscure other relevant indices. For example, body appreciation refers to positive attitudes towards the body and is known to be higher among men compared with women (Tylka, 2013). Furthermore, although body appreciation is negatively correlated with drive for muscularity (Campana, Tavares, Swami, \& da Silva, 2013), the two constructs should not simply be considered polar opposites. Rather, body appreciation offers a means of conceptualising men's body image in ways that go beyond indices of dissatisfaction. Furthermore, it is unclear in what ways men's body appreciation is associated with the Big Five domains.

In the present study, therefore, we examined associations between the Big Five domains, men's drive for muscularity, and body appreciation. By including measures of both drive for muscularity and body appreciation in the present work, we were able to examine the predictive power of the Big Five traits in relation to two different, albeit related, aspects of men's body image. Based on the above review, we predicted that Neuroticism would be positively associated with drive for muscularity and negatively associated with body appreciation. Although we did not expect robust associations between these body image variables and other Big Five traits, we nevertheless included the latter in our analyses.

\section{Method}

\section{Participants}

Participants of this study were 509 men recruited from the community in London, UK, and ranging in age from 18 to 59 years $(M=25.18, S D=8.28)$. Participants' mean self-reported body mass index (BMI) was $24.01(S D=4.90)$. Most participants were of British White ancestry (73.1\%), whereas $19.3 \%$ were of Asian descent, and $7.7 \%$ were of African Caribbean descent. In terms of educational qualifications, $36.0 \%$ had completed minimum secondary education, $28.3 \%$ were still in full-time education, $17.7 \%$ had an undergraduate degree, $7.5 \%$ had a postgraduate degree, and the remainder had some other qualification.

\section{Measures}

Drive for muscularity. We used McCreary and Sasse's (2000) Drive for Muscularity Scale (DMS), which consists of 15 items that tap an individual's desire to have a more muscular body. Items were rated on a 6 -point Likert-type scale ( $1=$ Always, $6=$ Never $)$ and were reverse-coded so that higher scores represent greater drive for muscularity. Although scores on the DMS have been shown to have a two-factor lower-order structure representing attitudinal and behavioural dimensions, the two subscales also load onto a single higher-order dimension (e.g., McCreary, Sasse, Saucier, \& Dorsch, 2004). Likewise, in the present study, the two subscale scores were strongly correlated $(r=.51)$ and we therefore computed a total DMS score by computing the mean of all 15 items. McCreary (2007) reported that the total DMS score has acceptable reliability and good construct, convergent, and discriminant validities. In the present study, Cronbach's $\alpha$ for this measure was .92.

Body appreciation. We measured body appreciation using the Body Appreciation Scale (BAS) developed by Avalos, Tylka, and Wood-Barcalow (2005). This is a 13-item measure that taps multiple aspects of positive body image and on which items are rated on a 5 -point Likert-type scale $(1=$ Never, $5=$ Always $)$. An overall score was computed as the mean of all 13 items, with higher scores reflecting more positive body appreciation. Among Western men, BAS scores have been shown to have a one-dimensional structure and demonstrate measurement equivalence between women and men (Tylka, 2013). In addition, the measure has been shown to have good psychometric properties among men, including good internal consistency and convergent validity (Swami et al., 2008; Tylka, 2013). In the present work, Cronbach's $\alpha$ for the BAS was .88 .

Big Five domains. Participants completed the NeuroticismExtraversion-Openness-Five-Factor Inventory (NEO-FFI; Costa and McCrae, 1992), which is a 60-item measure of the Big Five at the domain level. Each Big Five domain was measured on 12 items, which were rated for agreement on a 5-point Likert-type scale ( 1 =Strongly disagree, 5 = Strongly agree). Domain scores were computed as the mean of items associated with each factor. Costa and McCrae (1992) provided extensive evidence of the NEO-FFI's reliability and validity. Here, Cronbach's $\alpha$ for all five domains were $>.75$.

Subjective social status. We included a measure of subjective social status, namely the McArthur Ladder of Subjective Social Status (MLSSS; Adler, Epel, Castellazzo, \& Ickovics, 2000). This is a measure of social status presented as a 'social ladder' and in which participants are asked to select the rung that best describes the perceived social status. Scores range from 1 to 10 , with higher scores representing higher subjective social status.

Demographics. Participants were asked to report their demographics, consisting of age, ethnicity, educational qualifications, height, and weight (the latter two used to compute self-reported BMI as $\mathrm{kg} / \mathrm{m}^{2}$ ).

\section{Procedure}

Ethics approval for this study was obtained from the relevant university ethics committee. Recruitment was conducted on an opportunistic basis in several public locations in Greater London by six researchers. Once participation had been agreed, participants provided written informed consent and completed an anonymous paper-and-pencil version of the survey in a quiet location set up for the purposes of the project. The order of presentation of the scales was semi-randomised, with demographic items always appearing last. All participants took part on a voluntary basis and were not remunerated for participation. Upon returning their survey to the researchers, participants were provided with a debriefing sheet.

\section{Results}

Missing data ( $<2 \%$ of the total dataset) were replaced using the mean replacement technique. Descriptive statistics for, and bivariate correlations between, all variables are reported in Table 1. As can be seen, drive for muscularity was significantly and positively correlated with Neuroticism and with participant BMI. On the other hand, body appreciation was significantly and negatively correlated 
Table 1

Descriptive statistics and inter-scale bivariate correlations between all variables included in the present study.

\begin{tabular}{|c|c|c|c|c|c|c|c|c|c|}
\hline & (1) & (2) & (3) & $(4)$ & (5) & (6) & (7) & (8) & (9) \\
\hline $\begin{array}{l}\text { (1) Drive for muscularity } \\
\text { (2) Body appreciation } \\
\text { (3) Extraversion } \\
\text { (4) Agreeableness } \\
\text { (5) Conscientiousness } \\
\text { (6) Neuroticism } \\
\text { (7) Openness to experience } \\
\text { (8) Body mass index } \\
\text { (9) Subjective social status }\end{array}$ & & $-.32^{* *}$ & $\begin{array}{l}.05 \\
.22^{* *}\end{array}$ & $\begin{array}{r}.08 \\
.07 \\
-.11\end{array}$ & $\begin{array}{l}.05 \\
.06 \\
.23^{* *} \\
.10^{*}\end{array}$ & $\begin{array}{l}.29^{* *} \\
-.39^{* *} \\
-.04 \\
-.24^{* *} \\
-.14^{*}\end{array}$ & $\begin{array}{c}.03 \\
.08 \\
.17^{* *} \\
.10^{*} \\
.16^{* *} \\
-.17^{* *}\end{array}$ & $\begin{array}{c}.10^{*} \\
-.12^{*} \\
.11^{*} \\
-.11^{*} \\
.19^{* *} \\
.04 \\
-.10^{*}\end{array}$ & $\begin{array}{c}-.02 \\
.33^{* *} \\
.31^{* *} \\
.16^{* *} \\
.28^{* *} \\
.11^{*} \\
.15^{*} \\
.09^{*}\end{array}$ \\
\hline $\begin{array}{l}M \\
S D\end{array}$ & $\begin{array}{l}4.08 \\
1.16\end{array}$ & $\begin{array}{l}3.62 \\
0.62\end{array}$ & $\begin{array}{l}3.46 \\
0.42\end{array}$ & $\begin{array}{l}3.48 \\
0.58\end{array}$ & $\begin{array}{l}4.03 \\
0.49\end{array}$ & $\begin{array}{l}3.14 \\
0.52\end{array}$ & $\begin{array}{l}3.63 \\
0.62\end{array}$ & $\begin{array}{r}24.01 \\
4.90\end{array}$ & $\begin{array}{l}6.25 \\
1.70\end{array}$ \\
\hline
\end{tabular}

with Neuroticism and BMI, and positively correlated with Extraversion and subjective social status.

We next computed two separate hierarchical regressions with drive for muscularity and body appreciation, respectively, as the criterion variables. To examine for the possibility of curvilinear relationships with BMI, both BMI and $\mathrm{BMI}^{2}$ were entered in a first step along with subjective social status. The Big Five domains were entered in a second step. Multicollinearity diagnostics for both regressions indicated that multicollinearity was not a limiting issue (all VIFs <2.09). Consistent with our hypothesis, after controlling for the non-significant variance accounted for by subjective social status, BMI, and $\mathrm{BMI}^{2}(<1.0 \%)$, the model with drive for muscularity was significant, $F(8,508)=7.21, p<.001$, Adj. $R^{2}=.10$, with Neuroticism and participant BMI emerging as the only significant predictors (see Table 2).

In the model with body appreciation, the first step of the regression with subjective social status, BMI, and $\mathrm{BMI}^{2}$ was significant, $F(3,508)=27.26, p<.001$, Adj. $R^{2}=.13$. The second step of the regression was also significant, $F(8,508)=28.97, p<.001$, Adj. $R^{2}=.31$, with Neuroticism emerging as the strongest predictor. Subjective social status, BMI, and Extraversion also emerged as significant predictors (see Table 2). In separate analyses, we examined whether interactions between Neuroticism and other Big Five domains would emerge as significant predictors in a third step of the regressions. None of the interaction terms reached statistical significance.

\section{Discussion}

The results our work indicated that, once the effects of BMI and subjective social status were accounted for, Neuroticism was significantly associated with drive for muscularity (positively) and body appreciation (negatively). Neuroticism likely has a dual impact on body image: (i) directly, by increasing anxiety and insecurity over one's appearance, which in turn leads to appearance dissatisfaction, and; (ii) indirectly, through an attenuation of positive affect, which in turn reduces positive regard for one's own body (Swami et al., 2013). The present findings are consistent with this perspective, insofar as we found that Neuroticism was associated with greater drive for muscularity as well as lower body appreciation. In addition, to the extent that men who score highly on Neuroticism are more sensitive to appearance evaluation and rejection (Brookings, Zembar, \& Hochstetler, 2003) and have higher appearance orientation (Kvalem et al., 2006), they may show a stronger desire for idealised standards of beauty, such as greater muscularity.

We also found that Extraversion was positively associated with body appreciation in our sample of men. Previous studies have reported that women high in Extraversion have more positive body appreciation (Swami et al., 2008, 2013) and lower actual-ideal weight discrepancy (Swami et al., 2013), and our findings fit that general pattern. Kvalem et al. (2006) have shown that individuals high in Extraversion have more positive appearance evaluation; that is, they evaluate their appearance more positively than individuals who are more introverted, possibly as a function of their positive affect. In addition, to the extent that individuals high in Extraversion are more aware of appearance-related feedback, they may show greater investment in their appearance (Kvalem et al., 2006). The outcome of all this is that individuals who score highly on Extraversion may be more accepting, respectful, and protective of their bodies, which manifests as more positive body appreciation.

Taken together, the present findings may have useful practical implications for practitioners. For example, innovative intervention approaches could be developed based on the relationship between Neuroticism and body image. It has been suggested that mental health practitioners could routinely measure Big Five domains to determine if more extensive assessments of personality disorders related to Neuroticism should be conducted (Widiger \& Trull, 2007). Likewise, it may be possible to screen individuals for high Neuroticism scores, in order to determine whether testing for negative body image or disordered eating is necessary. Of course, from a public health perspective, more work will need to be conducted to demonstrate more than just concurrent correlations between Neuroticism and body image. That is, the public health significance of Neuroticism depends on its ability to reliably predict future incidence of negative body image and longitudinal work will be necessary in order to determine such a predictive relationship. More broadly, research on body image would benefit greatly from the types of causal models that have been used to link Neuroticism with physical health outcomes (e.g., Smith, 2006).

Future studies could also build on the present work in a number of other ways. First, use of the NEO-FFI to measure the Big Five in the present work meant that we were only able to examine domain-level scores. However, Neuroticism, like all the Big Five domains, can be viewed as a heterogeneous trait consisting of multiple, highly correlated but partially distinct facets, and it would be useful to examine associations between body image and these lower-order Big Five facets. Second, our study focused on direct relationships between the Big Five and body image, but future research should also consider indirect pathways (Kvalem et al., 2006). To that end, the inclusion of additional variables, such as attitudes towards media ideals and self-esteem, would help elucidate potential mediatory pathways between the Big Five domains and men's body image. Doing so may also help to elucidate why Neuroticism appears to be more strongly related with body appreciation than it is with drive for muscularity. Finally, we urge caution in interpreting the direction of causation of our findings: while the perspective we have adopted is consistent with the Big Five as higher-order domains, alternative explanations are possible (e.g., 
Table 2

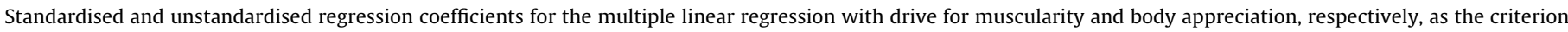
variables.

\begin{tabular}{|c|c|c|c|c|c|c|c|c|c|c|c|c|c|}
\hline \multirow[t]{2}{*}{ Step } & \multirow[t]{2}{*}{ Predictor } & \multicolumn{6}{|c|}{ Drive for muscularity } & \multicolumn{6}{|c|}{ Body appreciation } \\
\hline & & $B$ & $S E$ & $\beta$ & $t$ & $p$ & VIF & $B$ & $S E$ & $\beta$ & $t$ & $p$ & VIF \\
\hline \multirow[t]{3}{*}{1} & BMI & .03 & .02 & .13 & 2.02 & .044 & 2.00 & -.03 & .01 & -.23 & -3.94 & $<.001$ & 2.00 \\
\hline & $\mathrm{BMI}^{2}$ & -.01 & .01 & -.04 & -0.57 & .571 & 1.99 & .01 & .01 & .12 & 2.00 & .046 & 1.99 \\
\hline & Subjective social status & -.02 & .03 & -.03 & -0.65 & .517 & 1.04 & .13 & .02 & .36 & 8.56 & $<.001$ & 1.04 \\
\hline \multirow[t]{8}{*}{2} & BMI & .03 & .01 & .14 & 2.32 & .021 & 2.08 & -.03 & .01 & -.27 & -4.99 & $<.001$ & 2.08 \\
\hline & $\mathrm{BMI}^{2}$ & -.01 & .01 & -.07 & -1.12 & .263 & 2.01 & .01 & .01 & .08 & 1.59 & .112 & 2.01 \\
\hline & Subjective social status & -.06 & .03 & -.09 & -1.85 & .066 & 1.24 & .08 & .02 & .24 & 5.84 & $<.001$ & 1.24 \\
\hline & Extraversion & .05 & .04 & .07 & 1.39 & .167 & 1.20 & .05 & .02 & .12 & 2.93 & .004 & 1.20 \\
\hline & Agreeableness & .04 & .04 & .05 & 0.99 & .322 & 1.15 & -.01 & .02 & -.02 & -0.48 & .631 & 1.15 \\
\hline & Conscientiousness & -.01 & .04 & -.01 & -0.19 & .847 & 1.17 & .03 & .02 & .05 & 1.12 & .236 & 1.18 \\
\hline & Neuroticism & .28 & .04 & .29 & 6.56 & $<.001$ & 1.11 & -.18 & .02 & -.35 & -8.89 & $<.001$ & 1.11 \\
\hline & Openness to experience & -.02 & .05 & -.02 & -0.38 & .700 & 1.11 & -.03 & .02 & -.05 & -1.07 & .282 & 1.11 \\
\hline
\end{tabular}

Note. $\mathrm{BMI}=$ body mass index.

being body-confident may make a person more extraverted) and should be examined in future studies. These limitations notwithstanding, our findings highlight the importance of greater scholarly attention to the possible ways in which personality affects corporeal experiences.

\section{References}

Adler, N., Epel, E., Castellazzo, G., \& Ickovics, J. (2000). Relationship of subjective and objective social status with psychological and physiological functioning: Preliminary data in healthy, white women. Health Psychology, 19, 586-592. http://dx.doi.org/10.1037/0278-6133.19.6.586

Avalos, L., Tylka, T. L., \& Wood-Barcalow, N. (2005). The Body Appreciation Scale: Development and psychometric evaluation. Body Image, 2, 285-297. http://dx.doi.org/10.1016/j.bodyim.2005.06.002

Brookings, J. B., Zembar, M. J., \& Hochstetler, G. M. (2003). An interpersonal circumplex/five-factor analysis of the Rejection Sensitivity Questionnaire. Personality and Individual Differences, 34, 449-461. http://dx.doi.org/10.1016/ S0191-8869(02)00065-X

Campana, A. N. N. B., Tavares, M. C. G. C. F., Swami, V., \& da Silva, D. (2013). An examination of the psychometric properties of Brazilian Portuguese translations of the Drive for Muscularity Scale, the Swansea Muscularity Attitudes Questionnaire, and the Masculine Body Ideal Distress Scale. Psychology of Men and Masculinity, 14, 376-388. http://dx.doi.org/10.1037/a0030087

Costa, P.T., Jr., \& McCrae, R. R.(1992). Revised NEO Personality Inventory (NEO PI-R) and NEO Five-Factor Inventory (FFI): Professional manual. Odessa, FL: Psychological Assessment Resources.

Davis, C., Dionne, M., \& Shuster, B. (2001). Physical and psychological correlates of appearance orientation. Personality and Individual Differences, 30, 21-30. http://dx.doi.org/10.1016/S0191-8869(00)00006-4

Davis, C., Karvinen, K., \& McCreary, D. R. (2005). Personality correlates of a drive for muscularity in young men. Personality and Individual Differences, 39, 349-359. http://dx.doi.org/10.1016/j.paid.2005.01.013

Davis, C., Shuster, B., Blackmore, E., \& Fox, J. (2004). Looking good: Family focus on appearance and risk for eating disorders. International Journal of Eating Disorders, 35, 136-144. http://dx.doi.org/10.1002/eat.10250

John, O. P., Naumann, L. P., \& Soto, C. J. (2008). Paradigm shift to the integrative BigFive trait taxonomy: History, measurement, and conceptual issues. In O. P. John, R. W. Robins \& L. A. Pervin (Eds.), Handbook of personality: Theory and research (3rd ed., pp. 114-158). New York, NY: Guilford Press.

John, O. P., Robins, R. W. \& Pervin, L. A. (Eds.). (2008). Handbook of personality: Theory and research. New York, NY: Guilford Press.

John, O. P., \& Srivastava, S. (1999). The Big Five trait taxonomy: History, measurement, and theoretical perspectives. In L. A. Pervin \& O. P. John (Eds.), Handbook of personality: Theory and research (2nd ed., pp. 102-139). New York, NY: Guilford Press.

Kvalem, I. L., von Soest, T., Roald, H. E., \& Skolleborg, K. C. (2006). The interplay of personality and negative comments about appearance in predicting body image. Body Image, 3, 263-273. http://dx.doi.org/10.1016/j.bodyim.2006.04.002

McCreary, D. R. (2007). The Drive for Muscularity Scale: Description, psychometrics, and research findings. In J. K. Thompson \& G. Cafri (Eds.), The muscular ideal: Psychological, social, and medical perspectives (pp. 87-106). Washington, DC: American Psychological Association.

McCreary, D. R., \& Sasse, D. K. (2000). Exploring the drive for muscularity in adolescent boys and girls. Journal of American College Health, 48, 297-304. http://dx.doi.org/10.1080/07448480009596271

McCreary, D. R., Sasse, D. K., Saucier, D. M., \& Dorsch, K. D. (2004). Measuring the drive for muscularity: Factorial validity of the Drive for Muscularity Scale in men and women. Psychology of Men and Masculinity, 5, 49-58. http://dx.doi.org/10.1037/1524-9220.5.1.49

McLaren, V. V., \& Best, L. A. (2009). Female students' disordered eating and the Big Five personality facets. Eating Behaviors, 10,192-195. http://dx.doi.org/10.1016/ j.eatbeh.2009.04.001

Smith, T. W. (2006). Personality as risk and resilience in physical health. Current Directions in Psychological Science, 15, 227-231. http://dx. doi.org/10.1111/j.1467-8721.2006.00441x

Swami, V., Hadji-Michael, M., \& Furnham, A. (2008). Personality and individual difference correlates of positive body image. Body Image, 5, 322-325. http://dx.doi.org/10.1016/j.bodyim.2008.03.007

Swami, V., Taylor, R., \& Carvalho, C. (2011). Body dissatisfaction assessed by the Photographic Figure Rating Scale is associated with sociocultural, personality, and media influences. Scandinavian Journal of Psychology, 52, 57-63. http://dx.doi.org/10.1111/j.1467-9450.2010.00836.x

Swami, V., Tran, U. S., Hoffmann Brooks, L., Kanaan, L., Luesse, E.-M., \& Voracek, M. (2013). Body image and personality: Associations between the Big Five personality factors, actual-ideal weight discrepancy, and body appreciation. Scandinavian Journal of Psychology, 54, 146-151. http://dx.doi.org/10.1111/sjop.12014

Thomas, C. S., \& Goldberg, D. P. (1995). Appearance, body-image, and distress in facial dysmorphophobia. Acta Psychiatrica Scandinavica, 92, 231-236. http://dx.doi.org/10.1111/j.1600-0447.1995.tb09574.x

Thompson, J. K. \& Cafri, G. (Eds.). (2007). The muscular ideal: Psychological, social, and medical perspectives. Washington, DC: American Psychological Association.

Tylka, T. L. (2013). Evidence for the Body Appreciation Scale's measurement equivalence/invariance between US college women and men. Body Image, 10, 415-418. http://dx.doi.org/10.1016/j.bodyim.2013.02.006

Widiger, T. A., \& Trull, T. J. (2007). Plate tectonics in the classification of personality disorder: Shifting to a dimensional model. American Psychologist, 62, 71-83. http://dx.doi.org/10.1037/003-066X.62.2.7.1 